\title{
Abrupt or gradual increases in photoperiod for broiler breeders
}

\author{
P.D. Lewis ${ }^{\#}$ and R.M. Gous \\ Animal and Poultry Science, University of KwaZulu-Natal, Scottsville 3209, South Africa
}

\begin{abstract}
Cobb 500 broiler breeder females $(n=832)$, which had been raised to achieve a typical 20 -week body weight of $2.1 \mathrm{~kg}$, were subjected to an abrupt or gradual increase in photoperiod to determine the effects on reproductive performance. One group $(n=416)$ was reared on 8-h photoperiods till 19 weeks and abruptly transferred to $16-\mathrm{h}$ photoperiods. Another group $(\mathrm{n}=416)$ was reared on 8 -h photoperiods and given an initial increase to $12 \mathrm{~h}$ at 19 weeks, then weekly increments of $1 \mathrm{~h}$ to reach $16 \mathrm{~h}$ at 23 weeks. Both groups were reared in light-proofed facilities to 23 weeks and then moved to curtain-sided housing and maintained on 16-h daylengths to 60 weeks. There were no significant differences between the two lighting groups for age at sexual maturity, total egg production, egg mass output, mean egg weight to or body weight at 60 weeks. However, the birds given a single abrupt increment had a higher peak rate of lay whilst those given a gradual increase in daylength had better egg production at the end of the laying cycle. Broiler breeders transferred from closed rearing to curtain-sided adult accommodation (similar to that in which a large proportion of broiler breeders are housed) respond similarly to abrupt and gradual increases in daylength as do birds maintained throughout in controlled environment accommodation, and modern genotypes have similar responses to early genotypes.
\end{abstract}

Keywords: Broiler breeders, lighting, abrupt increase, sexual maturity, egg production

${ }^{\#}$ Corresponding author. E-mail: peter.lewis@dsl.pipex.com

\section{Introduction}

Under commercial conditions it is common practice for broiler breeders to be reared on 8 -h photoperiods, transferred to 11 or $12 \mathrm{~h}$ at about 20 weeks of age, and then given weekly increments of $1 \mathrm{~h}$ to reach 15 or $16 \mathrm{~h}$ by 24 weeks. However, turkey breeders, which like broiler breeders exhibit photorefractoriness, are normally given a single increase in photoperiod. In egg-type pullets, abrupt transfers to final photoperiod are reported to result in a similar egg output over the laying cycle to that of hens given a step-up lighting programme, but with a small increase in egg numbers, inferior persistency and a slight decrease in mean egg weight (Morris, 1980).

In lightproof accommodation, abrupt transfers at 19-20 weeks from 8 to $15 \mathrm{~h}$ for individually caged broiler breeders (Robinson et al., 1998a, b) or from 8 to $16 \mathrm{~h}$ for birds housed in litter-floor pens (Proudfoot et al., 1980) advanced age at sexual maturity by 1-7 d compared with birds given a gradual increase to final photoperiod. However, total egg production over the laying cycle was, as in egg-type hens, not significantly different because rate of lay at the end of the laying cycle was inferior to that for birds given a gradual increase in photoperiod (Robinson et al., 1998b). The effect on mean egg weight was variable, being significantly lower for abruptly increased birds in one trial (Robinson et al., 1998b) and unaffected in another (Proudfoot et al., 1980).

It is possible that the response of modern group-housed broiler breeders to an abrupt increase in daylength may be different from that of the early genotypes, and that birds reared in light-proofed facilities prior to a move to non-controlled environment housing at point of lay may respond differently from birds maintained throughout in controlled environment. This paper reports the effects of an abrupt or gradual increase in photoperiod on the reproductive performance of broiler breeder females. At 19 weeks, birds were transferred from 8 to $16 \mathrm{~h}$ abruptly or to $12 \mathrm{~h}$ followed by weekly increases of $1 \mathrm{~h}$ to reach $16 \mathrm{~h}$ at 23 weeks. Both groups were reared in light-proofed housing and moved to curtain-sided housing and a 16-h mixture of natural and artificial illumination at 23 weeks. 


\section{Materials and Methods}

Cobb broiler breeder females $(n=1520)$ were placed at $1 \mathrm{~d}$ of age on a litter floor in each of eight lightproof rooms $(\mathrm{n}=190)$ and given $2 \mathrm{~d}$ of continuous illumination, before being abruptly transferred to 16 $\mathrm{h}$ photoperiods on day 3 and to $8 \mathrm{~h}(07: 00-15: 00)$ on day 7. Illumination was provided by four $60 \mathrm{~W}$ incandescent lamps in each room, which produced a mean illuminance of $26 \pm 2.8$ lux at a height of $30 \mathrm{~cm}$. At 19 weeks four rooms were abruptly transferred to $16 \mathrm{~h}(07: 00-23: 00)$, and four rooms were transferred to $12 \mathrm{~h}(07: 00-19: 00)$, with weekly increments of $1 \mathrm{~h}$ to reach $15 \mathrm{~h}$ at 22 weeks. At 23 weeks, and within each lighting treatment, 13 birds were selected randomly from each of the four rearing rooms $(\mathrm{n}=52)$ and moved to each of eight pens in a curtain-sided adult house ( 2 lighting regimens $\mathrm{x} 8$ pens $\mathrm{x} 52$ birds $=832$ birds stocked at $\left.4.8 / \mathrm{m}^{2}\right)$ and given a 16-h mixture of natural and artificial light (04:00-20:00) until the end of the trial at 60 weeks. Natural daylength (sunrise to sunset) during the laying period progressively shortened from 13 to $11 \mathrm{~h}$, and then lengthened back to $13 \mathrm{~h}$ by depletion. Artificial illumination was provided between 04:00 and 08:00 and between $16: 00$ and $20: 00$ by a single $14 \mathrm{~W}$ compact warm-white fluorescent lamp located centrally in each pen at a height of $2 \mathrm{~m}$. Mean illuminance at bird-head height during periods of natural darkness was $9 \pm 0.6$ lux.

All birds were fed a $210 \mathrm{~g} \mathrm{CP} / \mathrm{kg}, 12.4 \mathrm{MJ}$ AME $/ \mathrm{kg}$ crumbled diet ad libitum until transfer to a $175 \mathrm{~g}$ $\mathrm{CP} / \mathrm{kg}, 11.9 \mathrm{MJ}$ AME $/ \mathrm{kg}$ pelleted diet scattered on the litter floor and controlled feeding at three weeks. At six weeks, the diet was changed to a $140 \mathrm{~g} \mathrm{CP} / \mathrm{kg}, 11.5 \mathrm{MJ} \mathrm{AME} / \mathrm{kg}$, and finally to a $145 \mathrm{~g} \mathrm{CP} / \mathrm{kg}, 11.5 \mathrm{MJ}$ AME $/ \mathrm{kg}$ layer diet from $5 \%$ egg production onwards, with the feed provided in troughs. Daily feed allocations during rearing were designed to achieve a mean body weight of $2.1 \mathrm{~kg}$ at $140 \mathrm{~d}$ (Table 1), with water availability limited to the first $5 \mathrm{~h}$ of each day from three weeks of age. After 20 weeks, the daily feed allocation was progressively increased to a peak of $170 \mathrm{~g} / \mathrm{bird}$ and then reduced by $5 \mathrm{~g} / \mathrm{bird}$ for each $5 \%$ decrease in rate of lay after peak production.

Forty-five birds (three samples of 15 birds) per room were bulk-weighed weekly from 1 to 20 weeks, all birds were individually weighed on transfer to the adult facilities at 23 weeks, and 20 birds (two boxes of 10 birds) per pen were bulk-weighed weekly between 20 and 32 weeks and at 4-weekly intervals through to depletion at 60 weeks. Egg numbers were recorded daily to pen, and eggs laid on a Monday, Wednesday and Friday were bulk weighed. Age at sexual maturity for a pen was defined as the second day on which the total number of eggs for two consecutive days first reached or exceeded the bird numbers in the pen (50 eggs/100 bird.day).

All data were subjected to a General ANOVA using a model from Statistix version 8 (Analytical Software, 2003).

\section{Results}

Table 1 Mean body weight (empty crops) recorded for Cobb broiler breeders reared on 8-h photoperiods

\begin{tabular}{cccc}
\hline Age (weeks) & Body weight $(\mathrm{kg})$ & Age (weeks) & Body weight $(\mathrm{kg})$ \\
\hline 1 & 0.09 & 11 & 1.27 \\
2 & 0.24 & 12 & 1.40 \\
3 & 0.35 & 13 & 1.49 \\
4 & 0.48 & 14 & 1.63 \\
5 & 0.59 & 15 & 1.77 \\
6 & 0.70 & 16 & 1.85 \\
7 & 0.77 & 17 & 1.92 \\
8 & 0.86 & 18 & 2.00 \\
9 & 1.01 & 19 & 2.07 \\
10 & 1.14 & 20 &
\end{tabular}


Age at sexual maturity for females subjected to an abrupt increase in photoperiod was not significantly different from that of the females given a gradual increase in photoperiod (Table 2). There were no significant differences between the two lighting groups for total egg production to 60 weeks, mean egg weight or egg mass output, though the hens given the single increase to $16 \mathrm{~h}$ tended to have a higher peak rate of lay $(\mathrm{P}=0.078)$ but inferior egg production $(\mathrm{P}=0.086)$ in the final stages of egg production (Table 2 and Figure 1). Body weight at 60 weeks and mortality between 23 and 60 weeks were similar for the two lighting treatments.

Table 2 Performance to 60 weeks for Cobb broiler breeders given a single increase in photoperiod from 8 to $16 \mathrm{~h}$ at 19 weeks or an initial increase to $12 \mathrm{~h}$ followed by weekly increases of $1 \mathrm{~h}$ to reach $16 \mathrm{~h}$ at 23 weeks

\begin{tabular}{lccc}
\hline \multirow{2}{*}{ Performance trait } & \multicolumn{2}{c}{ Increase in photoperiod } & \multirow{2}{*}{$\begin{array}{c}\text { Pooled s.e.d } \\
\text { Res df }=14\end{array}$} \\
\cline { 2 - 3 } & Abrupt & Gradual & \\
Age at 50\% lay (d) & 180.9 & 181.4 & 0.61 \\
Peak weekly rate of lay (\%) & 84.1 & 82.2 & 1.01 \\
Eggs per bird & 162.5 & 164.2 & 2.42 \\
Eggs per bird from 52 to 60 weeks & 28.9 & 30.2 & 0.67 \\
Egg mass (kg/bird) & 10.76 & 10.86 & 0.152 \\
Mean egg weight (g) & 66.2 & 66.1 & 0.19 \\
Mean egg weight from 52 to 60 weeks (g) & 71.8 & 71.3 & 0.32 \\
Body weight at 60 wk (kg) & 4.25 & 4.21 & 0.055 \\
Mortality 23-60 weeks (\%) & 8.3 & 8.7 & 3.02 \\
\hline
\end{tabular}

\section{Discussion}

The similar ages at sexual maturity for the two groups support the findings of Ciacciariello \& Gous (2005) that found the mean age at 50\% egg production for birds reared to 20 weeks on $8 \mathrm{~h}$ and given a single increase to $12 \mathrm{~h}$ was only $1 \mathrm{~d}$ later than that of birds abruptly transferred to $16 \mathrm{~h}$. Twelve-hour photoperiods had a similar potential ability to stimulate as $16 \mathrm{~h}$ (Lewis et al., 2004), and change in plasma luteinizing hormone concentration $6 \mathrm{~d}$ after broiler breeders were transferred from an 8-h to a 12.75-h photoperiod was similar to that of birds transferred to a 15.75 -h photoperiod (Dunn \& Sharp, 1990).

The similar total egg production to 60 weeks for the two groups agrees with the findings of Proudfoot et al. (1980) and Robinson et al. (1998b), and the superior egg production early in the laying cycle but inferior egg production at the end for the birds abruptly changed to $16 \mathrm{~h}$ (Table 2 and Figure 1) agrees with data reported by Robinson et al. (1998b) for broiler breeders and by Morris (1980) for egg-type hybrids. The mechanisms involved in triggering sexual maturation at the start and the onset of adult photorefractoriness (PR) at the end of a breeding season are both thought to be initiated by the initial transfer to a stimulatory daylength (Dawson, 2001), with the timing of the onset of PR being negatively related to photoperiod (Robinson \& Follett, 1982); birds on longer days go photorefractory sooner than birds on less stimulatory daylengths. It is possible, therefore, that the better persistency of the birds given a gradual increase in daylength was, in part, a result of the initial increase having been only to $12 \mathrm{~h}$ and not to $16 \mathrm{~h}$ and, as a consequence, a delay in the onset of PR.

It has been concluded that egg-type hybrids do not exhibit photorefractoriness because egg production at 72 weeks was similar for birds on 11-h and on 15-h daylengths. However, the birds on the longer photoperiod had initially been transferred to only $9 \mathrm{~h}$ followed by small weekly increments to reach $15 \mathrm{~h}$ at 27 weeks (Morris et al., 1995), and maybe the initial increase in daylength has more influence over the rate of lay at the end of the laying cycle than does the ultimate photoperiod. However, this does not appear to be true when increases are given late in the laying cycle because, in the final stages of the laying cycle, egg production for broiler breeders that had been progressively increased from 11 to $16 \mathrm{~h}$ between 35 and 54 weeks of age was inferior to that of birds held on $11 \mathrm{~h}$ (Lewis \& Gous, 2006). 
Although the similar mean egg weights concur with the findings of Proudfoot et al. (1980), they are not supported by data from Robinson et al. (1998b) that showed an abrupt transfer from 8 to $15 \mathrm{~h}$ at 20 weeks resulted in a significant reduction in mean egg weight. However, the authors of this last report noted that their findings were at variance with earlier observations. The similar body weights at 60 weeks for abrupt and gradual increases in daylength agree with the findings of Proudfoot et al. (1980).

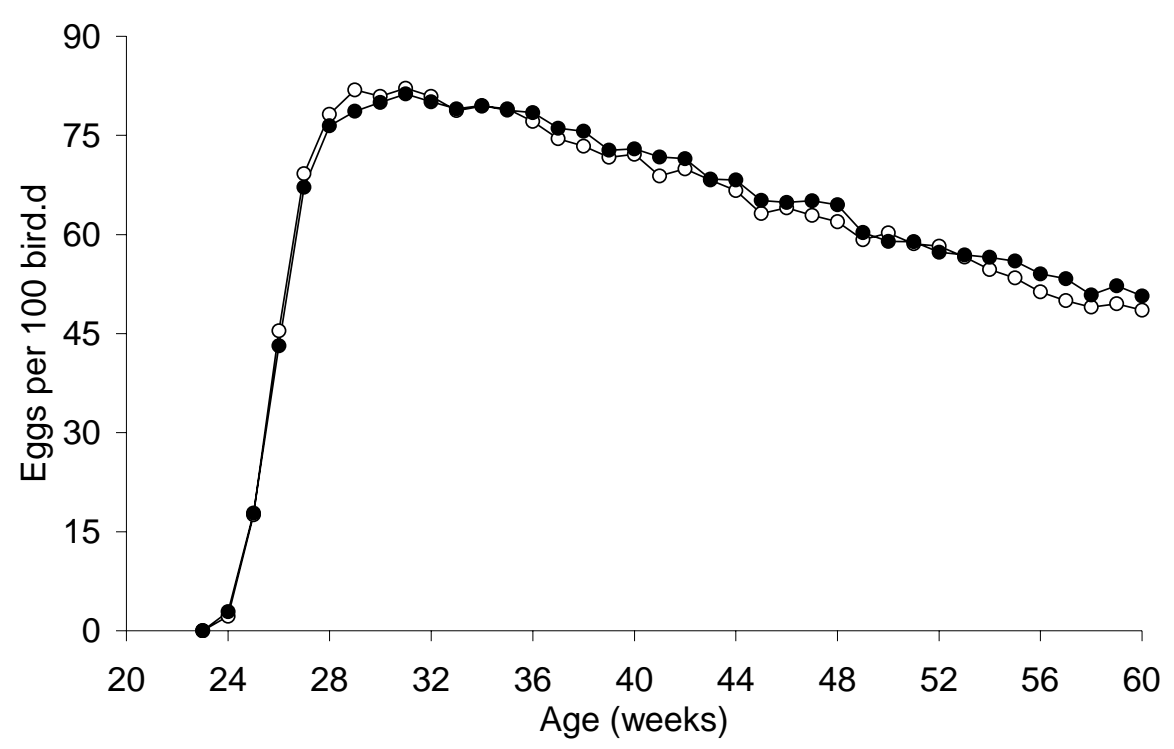

Figure 1 Weekly egg production (eggs per 100 bird.d) for Cobb broiler breeders given a single increase in photoperiod from 8 to $16 \mathrm{~h}$ at 19 weeks $(\circ)$ or an initial increase to $12 \mathrm{~h}$ followed by weekly increases of $1 \mathrm{~h}$ to reach $16 \mathrm{~h}$ at 23 weeks $(\bullet)$

Although these findings agree with earlier reports that an initial increase from 8 to $12 \mathrm{~h}$ at 19-20 weeks followed by weekly increments of $1 \mathrm{~h}$ results in similar performance to that of broiler breeders given a single increase to $16 \mathrm{~h}$, it should be noted that broiler breeders transferred to 11 or $12 \mathrm{~h}$, but without further increases in daylength, have had better total egg production than, but a similar mean egg weight to, birds transferred abruptly to $16 \mathrm{~h}$ (Ciacciariello \& Gous, 2005; unpublished data from University of KwaZuluNatal).

\section{Conclusions}

The similarity of the responses to abrupt and gradual increases in this trial show that they are not dependent on the birds being housed in controlled environment housing, that modern broiler breeder genotypes do not respond differently from early genotypes, and that the response of broiler breeders is similar to that of egg-type hybrids.

\section{Acknowledgements}

We wish to acknowledge the supply of day-old chickens and generous financial contributions from Cobb-Vantress, Siloam Springs, USA.

\section{References}

Analytical Software, 2003. Statistix version 8, Tallahassee, Florida, USA.

Ciacciariello, M. \& Gous, R.M., 2005. To what extent can age at sexual maturity of broiler breeders be reduced? S. Afr. J. Anim. Sci. 35, 73-82.

Dawson, A., 2001. The effects of a single long photoperiod on induction and dissipation of reproductive photorefractoriness in European starlings. Gen. Comp. Endocrinol. 121, 316-324.

Dunn, I.C. \& Sharp, P.J., 1990. Photoperiodic requirements for LH release in juvenile broiler and egg-laying strains of domestic chickens fed ad libitum or restricted diets. J. Reprod. Fertil. 90, 329-335. 
Lewis, P.D., Backhouse, D. \& Gous, R.M., 2004. Constant photoperiods and sexual maturity in broiler breeder pullets. Br. Poult. Sci. 45, 557-560.

Lewis, P.D. \& Gous, R.M., 2006. Constant and changing photoperiods in the laying period for broiler breeders allowed normal or accelerated growth during the rearing period. Poult. Sci. 85, 321-325.

Morris, T.R., 1980. Recent developments in lighting patterns for poultry in light-proof housing. Proc. South Pacific Poult. Sci. Convention, Auckland, New Zealand. pp. 116-124.

Morris, T.R., Sharp, P.J. \& Butler, E.A., 1995. A test for photorefractoriness in high-producing stocks of laying pullets. Br. Poult. Sci. 36, 763-769.

Proudfoot, F.G., Hulan, H.W. \& McRae, K.B., 1980. The effect of several different photoperiods on the performance of meat-type genotypes. Can. J. Anim. Sci. 60, 21-31.

Robinson, F.E., Renema, R.A., Bouvier, L., Feddes, J.J.R., Wilson, J.L., Newcombe, M. \& McKay, R.I., 1998a. Effects of photostimulatory lighting and feed allocation in female broiler breeders. 1. Reproductive development. Can. J. Anim. Sci. 78, 603-613.

Robinson, F.E., Renema, R.A., Bouvier, L., Feddes, J.J.R., Zuidhof, M.J., Wilson, J.L., Newcombe, M. \& McKay, R.I., 1998b. Effects of photostimulatory lighting and feed allocation in female broiler breeders. 2. Egg and chick production characteristics. Can. J. Anim. Sci. 78, 615-623.

Robinson, J.E. \& Follett, B.K., 1982. Photoperiodism in Japanese quail: the termination of seasonal breeding by photorefractoriness. P. Roy. Soc. Lond. 215, 95-116. 